\title{
Solution-Focused Group Therapy Program for Repeated-Drug Users
}

\author{
Kenji Yokotani ${ }^{1)}$ and Katsuhiro Tamura ${ }^{2)}$ \\ 1) Graduate School of Clinical Psychology, Niigata Seiryo University \\ 2) Treatment Sector, Niigata Prison
}

\begin{abstract}
Solution-focused approach was an effective treatment for drug abuse. Solution-focused therapy at the individual level showed treatment effects on drug users, but the therapy at the group level did not. On the basis of systemic therapies, we developed a solution-focused group therapy program for repeated-drug users in a Japanese prison. Our program was constituted of 12 sessions, all of which aimed to help achievement of clients' personal goal and development of clients' motivation to change their lifestyle. The program included collaborative structures to manage clients' aggressive behaviors. Our therapist's manual facilitated clients' solution talk and minimized their problem talk in group therapy. The program contents were also discussed from intrapersonal perspectives.
\end{abstract}

KEY WORDS : Repeated-Drug User, Solution-Focused Approach, Group Therapy, Solution talk.

\section{Introduction}

Drug-related offense was a severe problem. Around $60 \%$ of the drug-related offenses were committed by repeated-drug users in Japan (Ministry of Health, Labor, and Welfare, Pharmaceutical and Food Safety Bureau, Compliance and Narcotics Division, 2010). They suffered from severe mental health problems (Kilpatrick, Ruggiero, Acierno, Saunders, Resnick, \& Best, 2003) and bought a large volume of illegal drugs, which became a major fund source of illegal groups (Curtis \& Wendel, 2000). Ineffective treatment for them

Correspondence to Yokotani, Niigata Seiryo University, Room 5210, Suidocho, 1, 5939, Chuo district, Niigata city, Niigata prefecture, 951-8121, JAPAN.

E-mail: yokotani@n-seiryo.ac.jp could facilitate spread of illegal drugs and illegal groups. Therefore, effective treatment was essential not only to maintain their individual mental health, but also to build a peaceful and safe society.

Traditional treatment programs focused on problems of drug users. Therapist confronted clients' problems and made them "hit the bottom". Although these programs became very popular, treatment effects of the programs were in doubt. Actually, recent study pointed out that therapist's confrontation in counseling negatively predicted clients' cessation of drug use (Miller, Benefield, \& Tonigan, 1993).

Alternative treatment for drug-related users was Solution-Focused Approach (SFA) [Berg \& Reuss, 1998]. SFA aimed to construct solutions in collaboration with the client (De Shazer et al., 1986). SFA focused on the client's resources and emphasized on what each 
client had already done something useful (Kiser, Piercy, \& Lipchik, 1993; Miller \& Shazer, 2000). SFA's non pathological approach, utilization of clients' resources, and validation of clients' motivation were consistent with motivational interviewing methods, which was also popular in the treatment for drug abuse (Lewis \& Osborn, 2004).

SFA also showed treatment effects for drug users. The 60 offenders, including drug users, were randomly assigned to SFA and control groups (Lindforss \& Magnusson, 1997). The control group, which did not receive any treatment, committed a new offense after 12 months of their release more frequently than the SFA group. In the same line, 105 cocaine-dependent outpatients were randomly assigned to motivational interview and control groups (Stotts, Schmitz, Rhoades, \& Grabowski, 2001). The patients who received both individual motivational interview and detoxication program showed only $18 \%$ of relapse rate, whereas those who only received detoxication program were $36 \%$. These findings supported that individual SFA was an effective treatment for repeated drug users.

Still, we did not know whether treatment effects of individual SFA were generalizable to group SFA. For example, the 38 substance abusers were randomly assigned to Solution-Focused Group Therapy (SFGT) and control groups (Smock, Trepper, Wetchler, McCollum, Ray, \& Pierce, 2008). Participants who received 6 sessions of SFGT were not significantly different from those who received 6 sessions of purposeless individual counseling.
Similarly, the 37 university students with drinking problems were randomly assigned to one of three groups: 1) one motivational interviewing group session with feedback mail on their drinking; 2) mail feedback only; 3) no treatment (Walters, Bennett, \& Miller, 2000). Result showed that mail feedback group recovered better than those who received the group session or no treatment. These findings did not support the treatment effects for drug users at the group level.

Miller and Rollnick (2002) reviewed previous findings of motivational interviewing group therapy and clarified three limitations of the group therapy. First, group therapy cannot take enough time for clients' talk. Clients' talk about quitting drug predicted their actual cessation of drug use (Amrhein, Miller, Yahne, Palmer, \& Fulcher, 2003), so the limited time for their talk might weaken treatment effects. Second, clients also felt difficulties to express their emotion in group, even though therapist's validation of their emotion was a key to motivate clients to quit drug (Miller \& Rollnick, 2002). Hence, group therapy might not treat their emotion adequately. Third, therapist felt difficulties to manage group. Because substance use was positively correlated with aggressive behavior, hostility (McCormick, \& Smith, 1995) and even antisocial personality disorder (Robins, 1998), many repeated-drug users were aggressive and ganged up to attack other group members and therapist skillfully. Their mass attack was often too strong for the therapist to collaborate with them. Collaboration with them in group session could 
be more difficult than collaboration in individual session.

Although treatment effects of SFGT were not confirmed in previous findings, development of a SFGT program had academic and practical values. SFA was regarded as effective treatment program for drug users (Berg \& Reuss, 1998), but empirical evidence of SFA was limited (Gingerich, \& Eisengart, 2000). Development of SFA program could advance validation of SFA. Furthermore, group therapy was more cost-effective treatment than individual therapy. Effective group therapy program could increase the opportunities for drug users to receive effective treatment.

The present study proposed a new SFGT program for repeated-drug users in a Japanese prison. Our program overcame previous limitations of the group therapy. First, we took 12 sessions to conduct SFGT: The number of group sessions was twice of the previous study (e.g., Smock et al., 2008). The long duration of group therapy secured enough time for clients' talk. Meta-analysis of previous findings also suggested that the number of session positively affected treatment outcomes of drug users (Rubak, Sandbæk, Lauritzen, \& Christensen, 2005). The increased number of session should improve treatment outcomes of SFGT. Second, our program also ensured clients' personal talk with therapist. Clients' emotion was facilitated and validated during personal talk. Third, we developed collaborative structure and manual based on systemic therapies, such as Mental Research Institute Approach (Hasegawa, 1997; Watzlawick, Bavelas, Jackson, \& O'Hanlon,
1967; Watzlawick, Weakland, \& Fisch, 1974), Milan Approach (Palazzoli, \& Burt, 1990), and Collaborative Approach (Anderson \& Goolishian, 1992). The structure and manual should help therapist to corroborate with clients. Next section, we presented collaborative structure and manual. Then we offered the program contents of our SFGT. Lastly, we discussed our program from intrapersonal perspectives.

\section{Collaborative structure and therapist's manual to work with repeated-drug users}

Collaborative structure from physical and social perspectives

Many repeated-drug users were aggressive (McCormick, \& Smith, 1995; Robins, 1998), so therapist needed structure that could manage their aggressive behaviors. Our group therapy had two structures (Figure 1). At the former half, group members wrote down their individual answer to program handouts. This structure helped them to be ready to talk about themselves, rather than other drug users. Furthermore, the structure also minimized clients' mindless babble. The structure also helped therapist to talk to each client personally. Therapist's validation of their emotion and facilitation of their solution-focused thinking was effective treatment during personal talk (Miller \& Rollnick, 2002).

In the latter half, group members formed a ring and talk about their writings voluntarily. This structure had both positive and negative aspects. From positive aspects, group members 


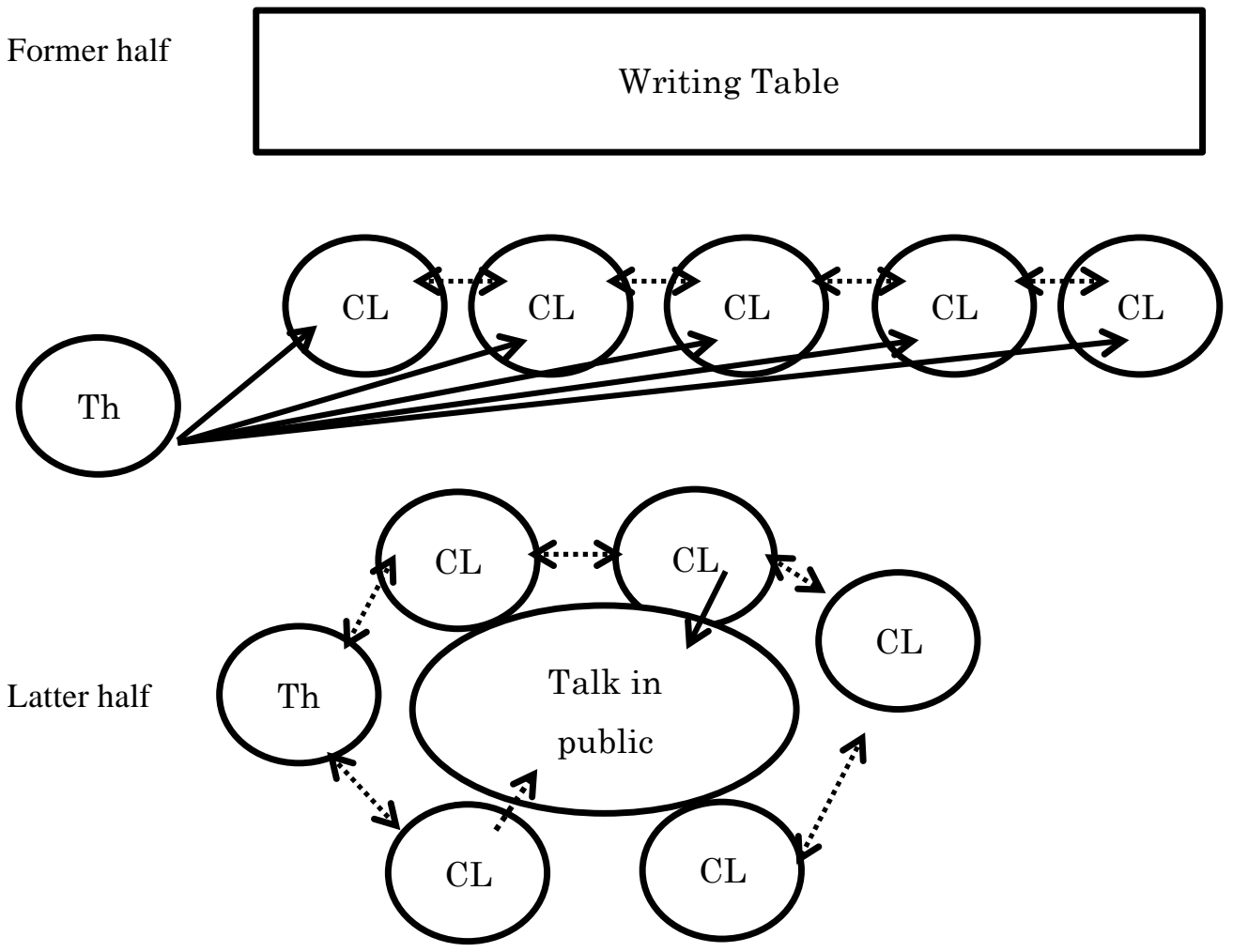

Figure 1 Two structures of Solution-Focused Group Therapy for repeated drug user

Note: Th: Therapist, CL: Client, group therapist maximized continuous lines and minimized dotted lines

could facilitate solution-focused talk with each other. From negative aspects, they might facilitate problem-focused talk or get into fight. To prevent their problem-focused talk and fight, therapist needed to manage group communication with care and skill. For example, when one member whispers during another members' talking, therapist needed to intervene in the one as the manager of group communication. Furthermore, some member might communicate nonverbally to the talking. For example, some member shoots another member a teasing glance. At this time, therapist needed to intervene in their teasing. Without intervention, their discussion could be escalated into a nonverbal fight, which was irrelevant with their solution (Watzlawick et al., 1967).

Figure 1 suggests that both structures minimized interaction among members. To prevent escalation of their aggressive behaviors, therapist needed to intervene in their aggressive interaction at the preliminary stage.

To manage client's aggressive behavior, group therapy also needed rules. Our programs had four rules (See table 1). Therapist should bring clients into compliance with these rules. Therapist's defense was allowed only if they attacked the rules. Basic explanation was 
following: To make group therapy safe, all members should not attack other members (Rule 1). To talk in a safe place, all members should respect other's talking (Rule 2). To secure each member's turn to talk, respect your and the other member's turn (Rule 3). To make the talk meaningful, talk honestly, but do not need to talk everything (Rule 4).

Without these rules, a member directly attacked other members, which harmed collaboration in group. Listening with half an ear to a speaker was regarded as relational aggression to some speaker. When the speaker perceived the aggression from the listener, the speaker harmed the listener in retribution.

Cycle of retribution easily destroyed group collaboration. Furthermore, group therapy needed to ensure each member to talk. Without clear turn, some could talk but others could not. The treatment effects for those who could not talk could be weakened. To focus on clients' actual solution, clients' solution needed to be based on actual experience. Fake story had little impact on their actual solution, so fake story would weaken solution-focused talk.
Therapist's manual from psychological perspectives

Based on these collaborative structures, therapist had a manual to facilitate solution-focused talk in group therapy. Our manual had three principles. The first principle was to maximize clients' solution talk. Clients' solution talk included clients' benefits of change, cost of the unchanged, optimistic attitudes to change, and commitment to change (Hoyt \& Berg, 2006; Miller, \& Rollnick, 2002). From social construction perspective, solution talk constructed clients' solvable reality (de Shazer et al., 1986; White \& Epston, 1990). Actually, clients' solution talk in counseling positively affected their actual solution (Amrhein et al., 2003), but therapists' encouragement to change was not (Mahrer, Gagnon, Fairweather, Boulet, \& Herring, 1994). Therapist's interests to specific theme facilitated clients to talk about the theme (Bavelas, Coates, \& Johnson, 2000; 2002), so s/he should maximize their solution talk through showing her (his) interest (Figure 2).

The second principle was to minimize

Table 1. Rules of Solution Focused Group Therapy for repeated-drug users

\begin{tabular}{lll}
\hline \multicolumn{2}{l}{ Rules } & Example \\
\hline 1 & Do not attack the other members & Warn when a member attacked another member verbally or \\
& and staffs & nonverbally \\
2 & Respect other's talking & Warn when someone did not listen to another member's \\
& & talking (nonverbally). \\
3 & Respect one's and other's turn & Warn when someone (verbally) interrupt another member's \\
& & turn. \\
4 & Talk honestly & Appreciate honesty (verbally) \\
\hline
\end{tabular}




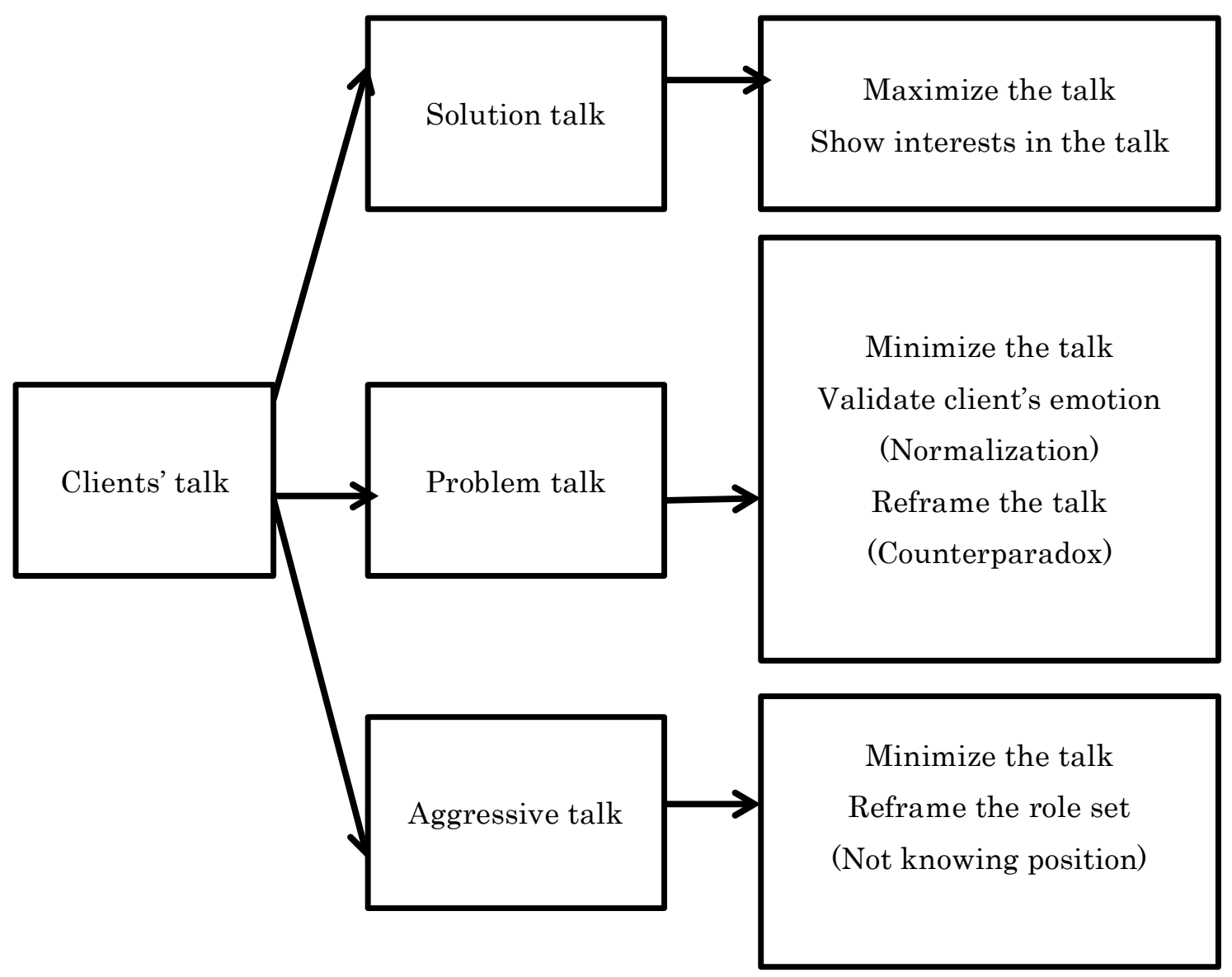

Figure 2. Therapist's manual on Repeated-Drug Users' talk

problem talk, but appreciated and reframed it. Problem talk involved clients' costs of change, benefits of the unchanged, pessimistic attitudes to change, and commitment to the unchanged (Hoyt \& Berg, 2006; Miller \& Rollnick, 2002). The problem talk constructed clients' problematic reality (de Shazer et al., 1986; White \& Epston, 1990). Actually, clients' problem talk in counseling affected their relapse of drug use (Amrhein et al., 2003). Furthermore, one problem talk affects another problem talk in group therapy (Miller, \& Rollnick, 2002). For example, clients easily found joy in competition for getting high. These talks were regarded as adverse effects on treatment (Miller, \& Rollnick, 2002), so therapist minimized their problem talk.

However, their problem talk reflected their emotion about their drug use. Their emotional expression was a key to enhance their motivation to quit drug, so therapist needed to validate their emotion. Normalization to their response was a way to validate their emotion. For example, when client said that "I cannot stop using drug", therapist replied that "Your feeling is exactly right. Many clients have your feeling when you try to quit drug. It takes a long way, so take your own time."

Furthermore, their problem talk needed to be reframed as facilitator of group therapy rather 
than impediment of the therapy. Showing respect to clients' honesty was the best way to validate their emotion and reframe the problem talk (Figure 2). For example, when client said that "I get high when I use drug. Why not use?", therapist responded like that "You are very honest. Your honesty was very important for therapeutic treatment, because your actual feeling is a key to understand your actual situation." This therapist's response was counter paradox (Palazzoli, \& Burt, 1990). If the client had talked his problem, he would commit to group therapy. If the client had stopped talking problem, the therapy could focus on solution talk. The group proceeded whether he would talk problem or stop talking problem. Most clients stopped talking problem, when therapist responded with the counter paradox.

The third principle was to minimize aggressive talk, but reframed it (Figure 2). Aggressive talk included client's attack to therapist, therapy, and other group members. Many group members tried to challenge therapist's authority. For example, "Are you repeated-drug user? (Therapist says no). You cannot understand our problem." "Talking in a prison is ineffective because drug use occurred outside of the prison". Therapist's defense against group member was the worst way to solve these aggressive talking. Actually, therapist's defense was ineffective on treatment (Miller et al., 1993).

The best way was "not-knowing position". Not-knowing position was therapist's learning attitudes to the clients' problem (Anderson, \&
Goolishian, 1992). The attitudes came from assumption that therapist did not know many things about clients' problem, so therapist needed to learn from the client who was the expert of the problem (Anderson, \& Goolishian, 1992). Hence, therapist needed to say "I cannot understand your problem fully. The person who can understand your problem is you." "Talking is very weak in anyway, but some members say the talking has very strong impact on their problem. Still, I do not know exact effects, actually." These responses made group free from debate about the authority of therapist.

Clients' aggressive talk also presumed that the therapist was an expert to solve their drug problem and they did not know how to quit drug. Therapist not-knowing position changed their presumption, because the responses implied clients' role as an expert speaker about drug use and therapist role as a listener about the drug use (Anderson, \& Goolishian, 1992). These implied role set decreased their challenge to therapist's authority, because authority of their problem was not therapist but clients. Furthermore, these role sets facilitated collaborative communication between clients and a therapist.

\section{Program Contents of Solution-Focused Group Therapy for Repeated-Drug Users}

With collaborative structure and therapist's manual, our program offered 12 sessions, all of which aimed to help achievement in clients' concrete goal and to enhance their motivation to change their current situation. Every session included individual feedback mails from 


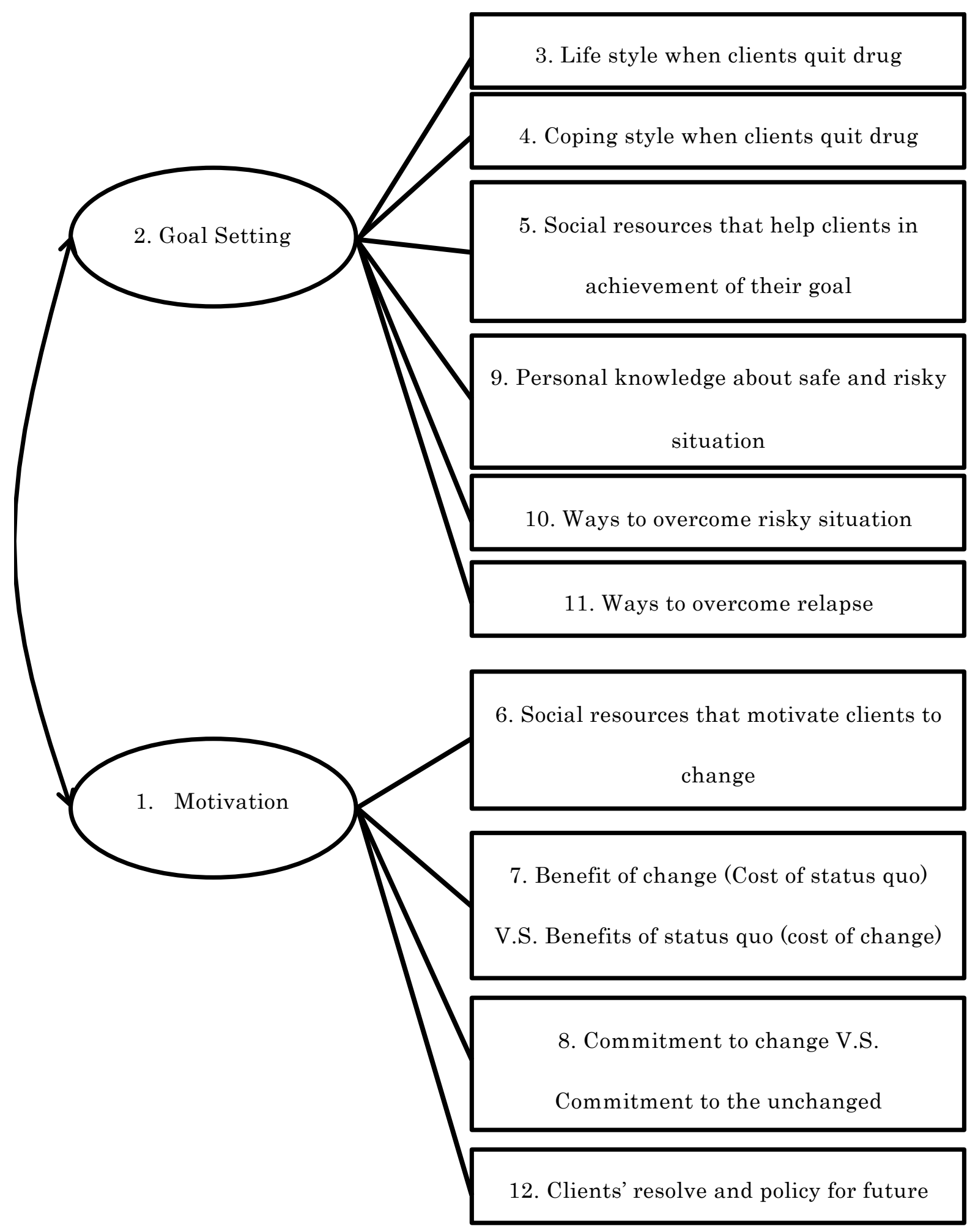

Figure 3. Solution Focused Group Therapy program for repeated-drug users 
therapist to them (Walters et al., 2000). The mails focused on their personal solutions. Figure 3 shows the schema of all sessions. The cores of our program were clients' concrete goal setting and development of their motivation. Figure 3 shows that all sessions were linked either of the two cores. Still, concrete goal setting affected clients' motivation and vice versa (Kiser, Piercy, \& Lipchik, 1993), so all sessions linked with both goal setting and motivation practically. We described achievement in clients' goal first and enhancement of their motivation next.

\section{Achievement in client's goal}

Clients' goal was defined by their ideal lifestyle after a few years of their release. The goal should neither be limited in drug use nor in their jail time. Drug use was regarded as a lifestyle problem (McLellan, Lewis, O'Brien, \& Kleber, 2000), so their goal needed to be set within their daily activity in society. Their goal also need to be concrete, which could be evaluated by them and therapist (De Shazer et al., 1986). The 2nd session asked their ideal goal after the release. The question covered a wide variety of daily activities (Table 2). Their goal was also utilized to scale their current situation (Table 2).

Furthermore, achievement in concrete goals required concrete methods. Therefore, following sessions facilitated them to find their concrete methods which they had already utilized [Table 2] (Miller \& de Shazer, 2000). For example, the 3rd session asked duration while they did not use drug. Their accumulated experience to stop using drug was the most powerful resources. Therapist needed to explore clients' experience in detail. The detailed description of their lifestyle revealed their concrete methods to detach themselves from drug. The 4th session focused on their coping behavior. Emphasis was on what each client had already managed to cope with drug using. The coping behavior should be derived from each client's experience. Therapist needed to keep not-knowing position. The 9th session asked exception when they did not use drug in spite of risky situation. Therapist needed to extract exception from each individual experience. The 10th session focused on client's personal processing, so their exception was smaller than the exception on 9th session. The smaller their exception is, the more they could use easily (Hasegawa, 1997; Watzlawick et al., 1974). Hence, therapist collaborated with clients to find their smallest exception. The 11th session asked coping behaviors of relapse. This session focused on client's personal experience how they stopped relapse.

\section{Enhancement of client's motivation}

Drug use was a lifestyle problem (McLellan et al., 2000), so their motivation to change their current lifestyle was the most important factors to prevent their drug abuse (e.g., Miller \& Rollnick, 2002). To enhance their motivation, therapist needed to focus clients" "solution talk" (Hoyt, \& Berg, 2006), because their desire to change could be socially and linguistically constructed through solution-focused communication (Miller, \& Shazer, 2000). 
Table 2. Program Contents of Solution Focused Group Therapy for repeated-drug users

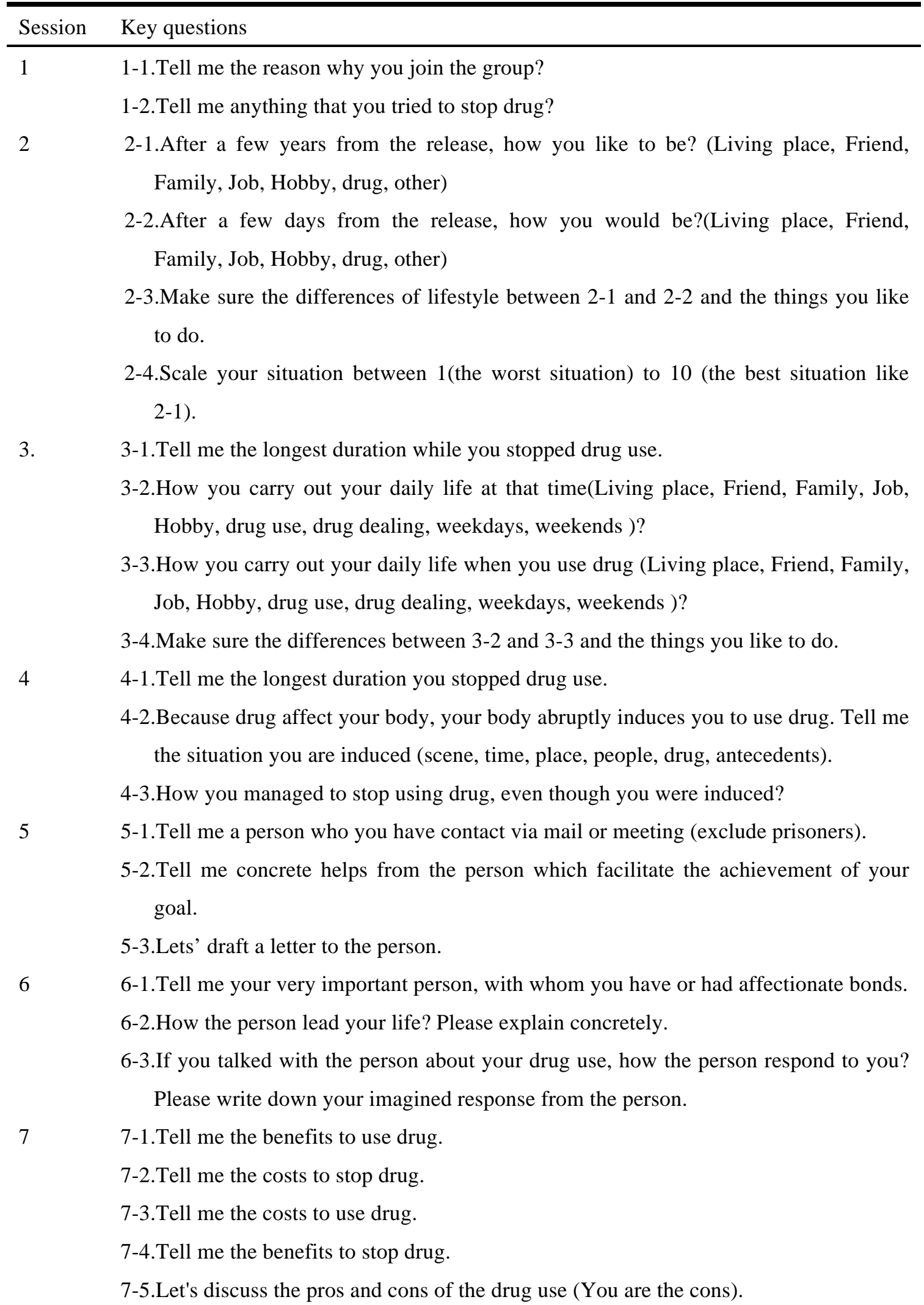


8-1.Tell me your attitudes toward taking drug (e.g., I cannot stop taking drug).

8-2.Tell me the evidence that support your attitudes.

8-3.Tell me your attitude toward stopping drug (e.g., I like to see my grandchildren in "clean").

8-4.Tell me the evidence that support your attitudes.

8-5.Let's discuss the pros and cons of the status quo (You are the cons).

9 9-1.Tell me the most frequent situation you use drug (Time place, person).

9-2.Although you were in the most frequent situation, you did not use drug. What's the difference? (Big differences, middle differences, small differences)

9-3.How you utilize these differences?

10 10-1.Tell me the situation a long while ago you use drug.(time place, person, thought, emotion, behavior, drug)

10-2.Tell me the situation a short while ago you use drug (time place, person, thought, emotion, behavior, drug)

10-3.Tell me the situation an instantly short while ago you use drug (time place, person, thought, emotion, behavior, drug)

10-4.Although you were in the most frequent situation, you did not use drug. What's the difference? (Big differences, middle differences, small differences)

10-5.How you utilize these differences?

11 11-1.When you had been released from the prison, how long days (months or hours) you did not use drug?

11-2.Tell me your life style at that days. (Living place, Friend, Family, Job, Hobby, drug use, drug dealing, weekdays, weekends )

11-3.After you used the first drug, how long days you did not use drug?

11-4.Tell me your life style at that days. (Living place, Friend, Family, Job, Hobby, drug use, drug dealing, weekdays, weekends )

11-5. What are differences between 11-2 and 11-4.

11-6.How you utilize these differences.

12 12-1.How will you carry your daily life after the release?

12-2.Tell me your effective methods to stop drug use. (Living place, Friend, Family, Job, Hobby, drug use, drug dealing, weekdays, weekends, time place, person, thought, emotion, behavior, drug)

12-3. Scale your current situation from the perspective of your ideal goal. 
Furthermore, their desire to change was more powerful predictor of their actual change than their reasoning of the change (e.g., Amrhein et al., 2003). Hence, therapists needed to validate their emotion to facilitate their emotional expression, including desire. Following session mainly focused on validation of their emotion and facilitation of their solution talk.

For example, the 1st session asked their reasons why they join group therapy. The most important thing was validation of their reasons. Any reasoning could be a signal of their emotion. Therapist's validation of their emotion facilitated clients' emotional expression (Kiser, Piercy, \& Lipchik, 1993). Furthermore, personalization of their reason was also important. Personalized reasoning helped clients to notice their personal emotion. The 6 th session asked their social resources who motivated them to quit drug. Especially, their significant other, such as grandmother and children were very effective to express their desire to quit drug use. Actually one offender said that "I cannot stop the drug for myself, but I can stop for my child". The 7th session asked both benefits and costs of their drug use. The 8th session also asked pessimistic and optimistic attitudes to their drug use. After summarized their answers, the therapist took a role of supporters to use drug, whereas group members took a role of opponents to use. Group member talked from opponent perspective. Therapist facilitated their opponent talk from supporter's perspective (Miller \& Rollnick, 2002). When some member took a role of supporters, therapist needed to intervene with the member to take opponent role. The discussion could reveal their ambivalent attitudes: They wanted to stop the drug, whereas they like to use drug (Miller \& Rollnick, 2002). Furthermore, they could talk their solution (Hoyt \& Berg, 2006). The 12th session asked their plan to carry out their daily life and scale their current situation. Members could project their own voice to stop drug use. Facilitation of their voice was the most effective way to enhance their motivation (Amrhein et al., 2003).

\section{Discussion}

Our program was based on systemic therapies (Anderson \& Goolishian, 1992; Hasegawa, 1997; Palazzoli, \& Burt, 1990; Watzlawick, Bavelas, Jackson, \& O'Hanlon, 1967; Watzlawick, Weakland, \& Fisch, 1974), so the program could be described well from interpersonal perspectives because systemic therapies emphasized interpersonal communication. Still, the program might not be described well from intrapersonal perspectives. In this section, we discussed the programs from intrapersonal perspectives.

\section{Clients' perspective}

From clients' perspective, using drug was pleasures of the moment. Clients did not think about future and past at the moment when they used. They just sought present pleasure. In other words, their short-sighted decision could foster their drug use. Still, their short-sighted vision might be slightly changed into long-sighted vision through SFA. This is 
because SFA facilitated them to view their future and to notice their successful past experience (de Shazer, 1986). This approach might help them to make decision not only from present perspectives but also from future perspectives. When they think about drug use, they could make decision based on their future plan. Most of them did not want to get into jail again and wanted to carry out their daily life outsides of the jail. Hence, their long-sighted vision could be an inhibitor to drug use.

Moreover, drug users did not take care about significant others at the moment when they used drug. They used drug only for themselves. In other words, their decision to use drug was made according to their egocentric thinking. However, their egocentric thinking might be slightly changed into other person-oriented thinking through our program. Our program helped them to explore their significant others. Most of them did not use drug in appearance of their children and parents. The significant other could be deterrent to use drug. Those who always think about their family might use drug less than those who did not.

\section{Therapist perspective}

Repeated-drug users were aggressive (McCormick, \& Smith, 1995; Robins, 1998) and ambivalent (Miller \& Rollnick, 2002), so therapist felt difficulty to collaborate with them. Especially when they attacked therapist verbally or they relapsed to use drug, therapist felt anger and distress. The simple expression of these feeling was confrontation with clients. Therapist's confrontation was a kind of counterattack to them, so the confrontation was exhalation of therapist's anger, rather than clients' one. Hence, the confrontation might be effective to therapist's mental health, but not clients' mental health. Although previous studies suggested that collaborative relationship with clients were key to treat them (Berg \& Reuss, 1998; Miller \& Rollnick, 2002), the ways how to collaborate with them and how to manage their aggressive behaviors in group were not discussed well. Our program described collaborative structures and therapist's manual to maximize their solution talk and to minimize their aggressive behaviors in group therapy. These structures and manual could promote effective group therapy and protect therapist from drug users' attack.

\section{Limitations}

Our study focused on male drug users. Hence, our program might not apply directly to female drug users. This is because female drug users often had specific family roles, such as child care (Marsh \& Miller, 1985). Programs for female drug users needed several sessions about their current family relationships. Furthermore, our program cannot apply to drug dealers directly. Because drug dealers make money through drug, they would lose job if they had stopped drug (Curtis \& Wendel, 2000). Their working styles and environments needed to be considered in future programs.

\section{Conclusion}

Despite these limitations, we developed a solution-focused group therapy program, which 
was currently applied in a Japanese prison. Treatment effects of SFA was reported clinically (De Shazer, 1984; De Shazer et al., 1986), but not empirically (Gingerich \& Eisengart, 2000). Empirical examination of SFA was necessary to be utilized as a primary treatment modality in broad areas. Detailed description of our treatment program could help to examine the effects of SFA in broad areas. Empirical evidence of SFA could offer effective treatment for repeated-drug users in broad areas and downsize the number of drug use in society.

\section{Acknowledgement}

The present study was supported by The Nikkoso Foundation for Safe Society (SZ2014A).

\section{References}

Amrhein, P. C., Miller, W. R., Yahne, C. E., Palmer, M., \& Fulcher, L. (2003). Client commitment language during motivational interviewing predicts drug use outcomes. Journal of consulting and clinical psychology, 71(5), 862-878.

Anderson, H., \& Goolishian, H. (1992). The client is the expert: A not-knowing approach to therapy. Therapy as social construction, 25-39.

Bavelas, J. B., Coates, L., \& Johnson, T. (2000). Listeners as co-narrators. Journal of personality and social psychology, 79(6), 941-952.

Bavelas, J. B., Coates, L., \& Johnson, T. (2002). Listener responses as a collaborative process: The role of gaze. Journal of Communication, 52(3), 566-580.

Berg, I. K., \& Reuss, N. H. (1998). Solutions step by step: A substance abuse treatment manual. New York and London: WW Norton.

Brent, D. A. (1995). Risk factors for adolescent suicide and suicidal behavior: mental and substance abuse disorders, family environmental factors, and life stress. Suicide and Life-Threatening Behavior, 25(s1), 52-63.

Curtis, R., \& Wendel, T. (2000). Toward the development of a typology of illegal drug markets. Crime prevention studies, 11, 121-152.

De Shazer, S. (1984). The death of resistance. Family Process, 23(1), 11-17.

De Shazer, S., Berg, I. K., Lipchik, E., Nunnally, E., Molnar, A., Gingerich, W., \& Weiner-Davis, M. (1986). Brief therapy: Focused solution development. Family process, 25(2), 207-221.

Gingerich, W. J., \& Eisengart, S. (2000). Solution - Focused Brief Therapy: A Review of the Outcome Research. Family process, 39(4), 477-498.

Hasegawa, K (1997) Kazokunai Paradox: Gyakusetsu to Koseishugi. [Paradox within family: paradox and constructionism]. Saiko shobo.

Hoyt, M. F., \& Berg, I. K. (2006). Case studies in couple and family therapy. In M. F. Hoyt (Ed.), The handbook of constructive therapies: innovative approaches from leading practitioners. 
Kilpatrick, D. G., Ruggiero, K. J., Acierno, R., Saunders, B. E., Resnick, H. S., \& Best, C. L. (2003). Violence and risk of PTSD, major depression, substance abuse/dependence, and comorbidity: results from the National Survey of Adolescents. Journal of consulting and clinical psychology, 71(4), 692-700.

Kiser, D. J., Piercy, F. P., \& Lipchik, E. (1993). The integration of emotion in solution-focused therapy. Journal of Marital and Family Therapy, 19(3), 233-242.

Lewis, T. F., \& Osborn, C. J. (2004). Solution - focused counseling and motivational interviewing: A consideration of confluence. Journal of Counseling \& Development, 82(1), 38-48.

Lindforss, L., \& Magnusson, D. (1997). Solution-focused therapy in prison. Contemporary Family Therapy, 19(1), 89-103.

Mahrer, A. R., Gagnon, R., Fairweather, D. R., Boulet, D. B., \& Herring, C. B. (1994). Client commitment and resolve to carry out postsession behaviors. Journal of Counseling Psychology, 41(3), 407--414.

Marsh, J. C., \& Miller, N. A. (1985). Female clients in substance abuse treatment. Substance Use \& Misuse, 20(6-7), 995-1019.

McCormick, R. A., \& Smith, M. (1995). Aggression and hostility in substance abusers: The relationship to abuse patterns, coping style, and relapse triggers. Addictive behaviors, 20(5), 555-562.
McLellan, A. T., Lewis, D. C., O'Brien, C. P., \& Kleber, H. D. (2000). Drug dependence, a chronic medical illness. JAMA: the journal of the American Medical Association, 284(13), 1689-1695.

Miller, G., \& Shazer, S. (2000). Emotions in solution - focused therapy: A re examination. Family process, 39(1), 5-23.

Miller, W. R., Benefield, R. G., \& Tonigan, J. S.(1993). Enhancing motivation for change in problem drinking: A controlled comparison of two therapist styles. Journal of Consulting and Clinical Psychology, 61(3), 455-461.

Miller, W. R., \& Rollnick, S. (2002). Motivational interviewing: Preparing people for change. Guilford press.

Ministry of Health, Labor, and Welfare, Pharmaceutical and Food Safety Bureau, Compliance and Narcotics Division. (2010) Yakubutsuranyo no genjyo to taisaku [Current situation and measure of drug abuse]

http://www.mhlw.go.jp/bunya/iyakuhin/yak ubuturanyou/dl/pamphlet_04.pdf

Palazzoli, M. S., \& Burt, E. V. (Eds.). (1990). Paradox and counterparadox: A new model in the therapy of the family in schizophrenic transaction. Rowman \& Littlefield.

Robins, L. N. (1998). The intimate connection between antisocial personality and substance abuse. Social Psychiatry and Psychiatric Epidemiology, 33(8), 393-399.

Rubak, S., Sandbæk, A., Lauritzen, T., \& Christensen, B. (2005). Motivational interviewing: a systematic review and 
meta-analysis. The British journal of general practice, 55(513), 305-312.

Smock, S. A., Trepper, T. S., Wetchler, J. L., McCollum, E. E., Ray, R., \& Pierce, K. (2008). Solution - Focused Group Therapy for Level 1 Substance Abusers. Journal of marital and family therapy, 34(1), 107-120.

Stotts, A. L., Schmitz, J. M., Rhoades, H. M., \& Grabowski, J. (2001). Motivational interviewing with cocaine-dependent patients: A pilot study. Journal of Consulting and Clinical Psychology, 69(5), 858-862.

Walters, S. T., Bennett, M. E., \& Miller, J. H. (2000). Reducing alcohol use in college students: A controlled trial of two brief interventions. Journal of Drug Education, 30(3), 361-372.

Watzlawick, P., Bavelas, J. B., Jackson, D. D., \& O'Hanlon, B. (1967). Pragmatics of human communication: A study of interactional patterns, pathologies, and paradoxes (Vol. 13). New York: Norton.

Watzlawick, P., Weakland, J. H., \& Fisch, R. (1974). Change: Principles of problem formation and problem resolution. WW Norton.

White, M., \& Epston, D. (1990). Narrative means to therapeutic ends. WW Norton \& Company. 